\title{
Feto-maternal outcome in patients with peripartum cardiomyopathy: a 5-year study in a tertiary care hospital in Kolar district, India
}

\author{
Sneha Singh*, Munikrishna M., Sheela S. R.
}

Department of Obstetrics and Gynecology, Sri Devaraj URS Medical College, Kolar, Karnataka, India

Received: 20 February 2020

Revised: 27 March 2020

Accepted: 01 April 2020

\author{
*Correspondence: \\ Dr. Sneha Singh, \\ E-mail: snehasingh4149@gmail.com
}

Copyright: () the author(s), publisher and licensee Medip Academy. This is an open-access article distributed under the terms of the Creative Commons Attribution Non-Commercial License, which permits unrestricted non-commercial use, distribution, and reproduction in any medium, provided the original work is properly cited.

\begin{abstract}
Background: Peripartum cardiomyopathy (PPCM) is a disorder of unknown cause in which initial left ventricular systolic dysfunction and symptoms of heart failure occur between the last month of pregnancy and the first 5 months postpartum. PPCM remains a diagnosis of exclusion. There have been numerous proposed causes including hormonal abnormalities, inflammation, viral pathogens, autoimmune response, and genetic predisposition. Aim of study was to study the clinical profile, risk factors, and the management along with obstetric and perinatal outcome, in women with peripartum cardiomyopathy.

Methods: This retrospective observational study was conducted on the antenatal women of age group of 18 years to 40 years, admitted in the labour ward of R. L. Jalapa hospital who presented with heart failure in last month of pregnancy till 5 months postpartum, without previously having a heart disease over the 5 year period, January 2015 to December 2019.

Results: Majority of the patients (15/18) presented with complaints of exertional dyspnoea. Mean LVEF at the time of diagnosis was $38.39 \%$. There were $5(27 \%)$ maternal mortality and all of them had global hypokinesia on echocardiography and presented in NYHA class III and IV. Two (11\%) out of eighteen patients had intrauterine death, and all the patients who had IUFD belonged to class IV. Four babies $(22.22 \%)$ had intrauterine growth restriction.

Conclusions: The present study came to conclusion that in rural tertiary center, maternal outcome and prognosis was poor as patients presenting to us were majority of them in cardiogenic shock and lower LVEF in terminal stages. The associated risk factors were preeclampsia, anemia and multiple gestation which could also contribute to the poor prognosis which was noticed in the study. Early recognition of the disease is of paramount importance as the clinical manifestations can conceal and can lead to high morbidity and mortality especially within 3 months postpartum.
\end{abstract}

Keywords: Heart failure, Peripartum cardiomyopathy, Pregnancy

\section{INTRODUCTION}

Peripartum cardiomyopathy (PPCM) is a disorder of unknown cause in which initial left ventricular systolic dysfunction and symptoms of heart failure occur between the last month of pregnancy and the first 5 months postpartum. ${ }^{1}$ PPCM remains a diagnosis of exclusion. No additional specific criteria have been identified to allow distinction between a peripartum patient with new onset heart failure and left ventricular systolic dysfunction as PPCM and another form of dilated cardiomyopathy. Therefore, all other causes of dilated cardiomyopathy with heart failure must be systematically excluded before accepting the designation of PPCM. 


\section{The first proposed criteria by Demakis and Rahimtoola}

- Development of cardiac failure in the last month of pregnancy or within 5 months of delivery

- Absence of another etiology of HF

- The absence of cardiac disease before pregnancy. ${ }^{2}$

Also, they proposed the addition of left ventricular systolic dysfunction with a left ventricular ejection fraction (LVEF) $<45 \%$, a fractional shortening $<30 \%$, or both with or without an LV end-diastolic dimension $>2.7$ $\mathrm{cm} / \mathrm{m}^{2}{ }^{3}$

It affects previously healthy pregnant women with a low incidence of $0.1 \%$ of pregnancies but has a high morbidity and mortality rate ranging from $7 \%$ to $50 \%$. The outcome of PPCM is highly variable. ${ }^{4}$ Risk factors includes advanced maternal age, preeclampsia, multiparity, multiple gestations, obesity, chronic hypertension, and the prolonged use of tocolytics. PPCM is more frequent in women at the extremes of childbearing ages and in older women of higher parity. ${ }^{5}$

The exact underlying mechanism of PPCM remains unknown. There have been numerous proposed causes including hormonal abnormalities, inflammation, viral pathogens, autoimmune response, and genetic predisposition. ${ }^{6-8}$

The main stay of treatment includes sodium restriction, diuretics, vasodilators and digoxin. ${ }^{9}$ Beta-blockers such as carvedilol have been shown to reduce mortality in dilated cardiomypothy. ${ }^{10}$ Anticoagulation with heparin should be initiated, if thrombus is noted on echocardiography. Warfarin can be given postpartum. ${ }^{10}$ The recovery of ventricular function does not assure a good prognosis of the next pregnancy, in addition to the hypothesis about the recurrence of the disease, decreased $\mathrm{EF}$, and heart failure in the peripartum period. ${ }^{11}$

Aim of the study was to study the risk factors, clinical profile and the management along with obstetric and perinatal outcome, in women with peripartum cardiomyopathy.

\section{METHODS}

This retrospective observational study was done on all antenatal women belonging to reproductive age group of 18 years to 40 years and was admitted in labour ward of this hospital and presented with heart failure in last month of pregnancy till 5 months postpartum, without previously having a heart disease.

Materials for this study were obtained by reviewing the records in the labour ward delivery register, the obstetric theatre, case notes from the medical records department and records of the new-born special care unit of the teaching hospital over the 5-year period, January 2015 to December 2019. Baseline data recorded included age, parity, gestational age, type of lesion, duration of disease, time of diagnosis, risk factors, treatment history, NYHA functional class, maternal complications, mode of delivery and indication of caesarean section, neonatal outcome and admission to NICU were noted. In case maternal mortality, the cause of death was noted. Clinical and laboratory findings electrocardiograms (ECG), chest X-ray films, echocardiograms, hemoglobin levels on diagnosis, treatments and course in the intensive care unit (ICU). All echocardiograms were performed in the hospital echo-lab by a trained cardiology echocardiographist. Echocardiograms were obtained for diagnosis and shortly following diagnosis as per protocol. All patients went through at least one detailed fetal ultrasound scan during pregnancy and were cared for by an obstetrician during pregnancy.

\section{Statistical analysis}

The statistical analysis was done by using SPSS software.

\section{RESULTS}

Out of 15,000 delivered patients during study period, 150 women had heart disease. Out of these, 18 (12\%) had peripartum cardiomyopathy. Mean age at the time of presentation was 26 years and multiparous consisted of 8 cases $(44.4 \%)$. Majority of the patients $(15 / 18)$ presented with complaints of exertional dyspnoea. Mean LVEF at the time of diagnosis was $38.39 \%$. There were $5(27 \%)$ maternal mortality and all of them had global hypokinesia on echocardiography and presented in NYHA class III and IV. Two (11\%) out of eighteen patients had intrauterine death, and all the patients who had IUFD belonged to class IV of NYHA. Four babies (22.22\%) had intrauterine growth restriction.

Table 1: Age, parity, onset of symptoms.

\begin{tabular}{|c|c|c|}
\hline Factors & $\begin{array}{l}\text { No. of patients } \\
(n=18)\end{array}$ & Percentage \\
\hline \multicolumn{3}{|l|}{ Age (years) } \\
\hline $18-20$ & 4 & $22.22 \%$ \\
\hline $21-25$ & 6 & $33.33 \%$ \\
\hline $26-30$ & 4 & $22.22 \%$ \\
\hline$>30$ & 4 & $22.22 \%$ \\
\hline Mean \pm SD & $26.33 \pm 5.73$ & \\
\hline Median (IQR) & $25(22-30)$ & \\
\hline \multicolumn{3}{|l|}{ Parity } \\
\hline Primigravida & 10 & $55.56 \%$ \\
\hline Multigravida & 8 & $44.44 \%$ \\
\hline \multicolumn{3}{|l|}{ Onset } \\
\hline 37-42 weeks & 14 & $77.78 \%$ \\
\hline $\begin{array}{l}\text { Within } 1 \text { week after } \\
\text { delivery }\end{array}$ & 3 & $16.67 \%$ \\
\hline After 1 week of delivery & y 1 & $5.56 \%$ \\
\hline
\end{tabular}

The Table 1 shows that, out of total 18 subjects, $1 / 3^{\text {rd }}$ were in the age group 21-25 years, with mean age group 
being $26.33 \pm 5.73$ years. 10 out of $18(55.56 \%)$ were primigravida while $44.44 \%$ were multigravida. The time of onset of the peripartum cardiomyopathy was highest at $37-40$ weeks with $77.78 \%$, followed by $16 \%$ within a week after delivery and $5.56 \%$ after the $1^{\text {st }}$ week of delivery.

Table 2: Presenting features and risk factors.

\begin{tabular}{|lll|}
\hline $\begin{array}{l}\text { Presenting features } \\
\text { and risk factors }\end{array}$ & $\begin{array}{l}\text { No. of patients } \\
(\mathbf{n = 1 8})\end{array}$ & Percentage \\
\hline NYHA grading & & \\
\hline 1 & 3 & $16.67 \%$ \\
\hline 2 & 5 & $27.78 \%$ \\
\hline 3 & 8 & $44.44 \%$ \\
\hline 4 & 2 & $11.11 \%$ \\
\hline Anaemia & 5 & $27.78 \%$ \\
\hline Multiparity & 8 & $44.44 \%$ \\
\hline Hypertensive disease & 5 & $27.78 \%$ \\
\hline Twin gestation & 2 & $11.11 \%$ \\
\hline
\end{tabular}

In the study most of the peripartum cardiomyopathy cases were of NYHA grade 3 with $44.44 \%$, followed by grade 2 with $27.78 \%$. Risk factors present in this study for developing peripartum cardiomyopathy were hypertension during pregnancy, anemia and twin gestation. $5(27.78 \%)$ cases presented with anaemia and 5 $(27.78 \%)$ had preeclampsia, while 3 were multiparous and 2 had twin gestation.

Table 3: Investigations.

\begin{tabular}{|lll|}
\hline Investigations & $\begin{array}{l}\text { No. of patient } \\
(\mathbf{n = 1 8})\end{array}$ & Percentage \\
\hline ECG changes & & \\
\hline AF & 1 & $5.56 \%$ \\
\hline Sinus tachycardia & 8 & $44.44 \%$ \\
\hline ECHO-ejection fraction $(\%)$ & 1 & $5.56 \%$ \\
\hline$<=25$ & 5 & $27.78 \%$ \\
\hline $26-35$ & 12 & $66.67 \%$ \\
\hline $36-45$ & $38.39 \pm 6.11$ & \\
\hline Mean \pm SD & $40(34-43)$ & \\
\hline Median (IQR) & 18 & $100.00 \%$ \\
\hline $\begin{array}{l}\text { Mitral regurgitation } \\
\text { (trivial) }\end{array}$ & 18 & $100.00 \%$ \\
\hline $\begin{array}{l}\text { Tricuspid regurgitation } \\
\text { (trivial) }\end{array}$ & 18 & $16.67 \%$ \\
\hline $\begin{array}{l}\text { Left ventricular } \\
\text { hypertrophy }\end{array}$ & 3 & $11.11 \%$ \\
\hline Left atrial enlargement & 2 & \\
\hline
\end{tabular}

Table 3 shows us the investigation findings of women with presenting with peripartum cardiomyopathy. 8 out of 18 cases $(44.44 \%)$ had sinus tachycardia on ECG. Majority of the cases $(66.67 \%)$ had ejection fraction between $36-45 \%$, While 5 cases $(27.78 \%)$ had $\mathrm{EF}$ between $26-35 \%$ and only one case had EF less than $25 \%$. All the cases had mitral valve as well as tricuspid valve regurgitation. But, only 3 cases had left ventricular hypertrophy and only 2 cases had left atrial enlargement.

Table 4: Maternal outcome.

\begin{tabular}{|lll|}
\hline Maternal outcome & $\begin{array}{l}\text { No. of patients } \\
(\mathbf{n = 1 8})\end{array}$ & Percentage \\
\hline Abruption & 2 & $11.11 \%$ \\
\hline Arrythmia & 1 & $5.56 \%$ \\
\hline CCF & 3 & $16.67 \%$ \\
\hline Vaginal delivery & 8 & $44.44 \%$ \\
\hline Caesarean section & 10 & $55.56 \%$ \\
\hline Days of hospital stay $($ days $)$ & \\
\hline Mean+SD & $10 \pm 5.43$ & \\
\hline Median (IQR) & $11(5-15)$ & $44.44 \%$ \\
\hline Blood transfusion & 8 & $83.33 \%$ \\
\hline ICU admission & 15 & $27.78 \%$ \\
\hline Maternal Mortality & 5 & Percentage \\
\hline $\begin{array}{l}\text { Only for survived } \\
\text { patients }\end{array}$ & $\begin{array}{l}\text { No. of patients } \\
(\mathbf{n = 1 3})\end{array}$ & $100.00 \%$ \\
\hline $\begin{array}{l}\text { Prolonged stay of } \\
\text { survived patients }\end{array}$ & 13 & \\
\hline
\end{tabular}

In this study congestive cardiac failure was documented in 3 cases $(16.67 \%)$, abruption in $2(11.11 \%)$ and arrythmia in $1(5.56 \%)$ case. $8 / 18(44.44 \%)$ women had vaginal delivery and 10/18 (56.56\%) underwent caesarean section for obstetric causes. The mean hospital stay was $10 \pm 5.43$ days. ICU admission was required in 15 cases $(83.33 \%)$ and blood transfusion in 8 cases (44.44\%). Maternal mortality was 5 out of total 18 $(27.78 \%)$ with all the 13 survivors had prolonged stay.

Table 5: Fetal outcome.

\begin{tabular}{|c|c|c|}
\hline Fetal outcome & $\begin{array}{l}\text { No. of patients } \\
(n=18)\end{array}$ & Percentage \\
\hline Neonatal mortality & 2 & $11.11 \%$ \\
\hline NICU admission & 7 & $38.89 \%$ \\
\hline Cause of NICU & $\begin{array}{l}\text { No. of patients } \\
(n=7)\end{array}$ & Percentage \\
\hline IUGR & 4 & $57.14 \%$ \\
\hline Respiratory distress & 3 & $42.86 \%$ \\
\hline
\end{tabular}

Tables 5 shows the fetal outcome with NICU admission which was required in 7 cases $(38.89 \%)$, while neonatal mortality was $2(11.11 \%)$. Out of 7 NICU admissions, 4 cases $(57.14 \%)$ had intrauterine growth retardation, while 3 cases $(42.86 \%)$ had respiratory distress.

\section{DISCUSSION}

Peripartum cardiomyopathy is a relatively rare disease complicating the peripartum period. PPCM being a disease of exclusion with unclear etiopathogenesis. Several unconfirmed aetiologies such as infective viral triggers, a pregnancy-mediated abnormal hemodynamic response, myocarditis, autoimmune factors, inflammatory 
mediators, prolonged tocolysis and selenium deficiency have been postulated. ${ }^{12}$ PPCM has also been speculated to be mediated by a $16 \mathrm{kDa}$ fragment of prolactin. Its diagnosis is based on signs and symptoms of heart failure with no other explainable causes occurring in preceding 5 months and within 1 month of delivery. ${ }^{1}$

In the present study the incidence of cardiac disease in pregnant women was $1 \%$ (150 out of 15000) which is comparative to the study by susheela et al. Out of these, $18(12 \%)$ had peripartum cardiomyopathy. Mean age at the time of presentation was 26 years and primigravida formed the majority with $55.56 \%$ of the total study population. Most patients had onset of symptoms in the 37 to 40 weeks period of gestation and the most common mode of delivery was caesarean section $(55.56 \%)$. The most common symptom at presentation was dyspnoea on exertion NYHA 3 (44.44\%) and the most common associated co-morbidity was hypertensive disease $(27.78 \%)$. The maternal mortality in this study was $27.78 \%$. Neonatal mortality in this study was $2(11.11 \%)$. Risk factors for PPCM which have been previously studied include multiparity, advanced maternal age, multiple gestation, African descent, gestational hypertension, preeclampsia, family history, smoking). Elkayam et al, had previously demonstrated that PPCM can occur at any age but a higher incidence was noted in women aged 30 years or more, most patients in this study were in the age group of 20 to 25 years $(33.33 \%)$ mean age of 26.33 which is similar to the study by Debasmita et al. ${ }^{13}$ However, another similar Indian study by Anuja et al had a mean age of presentation of 29.76 years also in this study primigravidae formed the majority with $55.56 \%$ (multigravida were $44.44 \%$ ). ${ }^{14}$

The presentation of PPCM patients is highly variable. Patients may range from mildly symptomatic to the New York Heart Association (NYHA) class IV. Furthermore, a high index of suspicion is required when making the diagnosis of PPCM given the significant overlap of symptoms related to early PPCM compared to the expected physiologic changes associated with pregnancy. Signs and symptoms such as pedal edema, dyspnoea on exertion, orthopnea, and persistent cough are common in pregnancy or other pregnancy-related pathologies (i.e., anemia) which can lead to delay in diagnosis. However, the most common initial presentation is NYHA functional class III or IV. Some patients may even present with ventricular arrhythmias or cardiac arrest. ${ }^{15}$ Similarly the most common symptom at presentation in this study was dyspnoea on exertion NYHA III in $44.44 \%$ $(8 / 18)$ patients. The predominant risk factors identified in this study were hypertensive disease in pregnancy $27.78 \%(5 / 18)$ followed by mild to moderate anemia $27.78 \%(5 / 18)$ and twin gestation $11.11 \%(2 / 18)$. In the study by Anuja et al they had demonstrated twin pregnancy as a risk factor for PPCM. ${ }^{14}$ They had 2 patients out of 25 who had developed PPCM which is similar to this study (2 out of 18). However, these results are not in accordance with those of Elkayam et al. ${ }^{16}$ For diagnosing PPCM among clinical, echocardiographic, and hemodynamic variables previously shown, echocardiography is valuable for formulating prognosis of recovery and course of disease. In present study, in cardiac investigations the most common ECG manifestation was sinus tachycardia $(44.44 \%)$ and in majority of patient's echocardiography ejection fraction is in the $36-45 \%$ range.

Patients with diagnosed PPCM should be referred to tertiary care centers so that better care can be given to mother and fetus. Even, though delivery of the fetus decreases the metabolic demands on the mother it adds disadvantage of increasing afterload due to the loss of the placental low-resistance bed. It is always a better option to terminate the pregnancy for the sake of mother. The prefereble mode of delivery is vaginal because of low complication rates. Complications, such as endometritis and pulmonary embolism are seen to occur significantly more in association with cesarean delivery (up to $75 \%$ ). In this study most deliveries were by caesarean route $55.56 \%(10 / 18)$ as compared to vaginal $44.44 \%(8 / 10)$. This was similar to the study by Binu et al $(59 \%) .{ }^{12}$ However vaginal delivery was the most common delivery mode in other similar studies such as in the study by Anuja et al (64\% vaginal) and in Debasmita et al (94\% vaginal deliveries). ${ }^{13,14}$ Increased incidence of caesarean in present study is attributed to obstetric causes requiring urgent surgical interventions such as fetal distress (3/18), oligohydramnios, twin pregnancy and breech presentation $(1 / 18)$ and previous LSCS (4/18).

Out of the 18 patients 16 were singleton and 2 were twin pregnancies. All the 18 mothers gave birth to live babies however 2 babies died because of birth asphyxia within 5 days of birth. Total of $7(38.8 \%)$ babies had required NICU admissions. Out of these 7 babies, 4 (57.14\%) had intra uterine growth retardation and $3(42.86 \%)$ were in respiratory distress. This study showed favorable results with regards to fetal outcomes and this could be because of most patients developing the heart failure symptoms late in the third trimester or in the post-partum period and thus the causative factors did not have much influence on fetal health. Fetal outcome being so good can also be because of study center being a tertiary care center with all round availability of all the department specialists and a well-equipped neonatal ICU.

Patients were managed in the ICU following diagnosis and cared for by a multidisciplinary team including intensive care specialists, cardiologists and maternal fetal medicine obstetricians. Treatment included diuretics, beta blockers, ACE inhibitors, nitrates and ventilation support as needed. The use of pentoxifylline, IV immunoglobulin, immunosuppressive therapy, and bromocriptine are the recent modes of therapy as per the etiology postulated, and can be helpful for management of PPCM, decreasing maternal mortality. ${ }^{15}$ Most of the studies have shown maternal mortalities ranging from $18 \%$ to $56 \% .^{12,16,17}$ In this study it was $27.78 \%(5 / 18)$. In the study by 
Debasmita et al it was $14 \%(5 / 36) .{ }^{13}$ Anuja et al had showed a high mortality rate of $54.54 \%(6 / 11) .{ }^{14}$ Maternal mortality in present study was affected by the late referral from primary care center and also few of them has presented to study center with heart failure postpartum. Therefore, early diagnosis and prompt management is very important step for survival of patients in PPCM cases. There can be persistent cardiomyopathy and thromboembolism in postpartum period. Thromboembolism in PPCM may be due to the hypercoagulable state of pregnancy itself or stasis of blood due to left ventriculardysfunction. ${ }^{7}$ Left ventricular thrombus is common in PPCM patients with a left ventricular ejection fraction of $<35 \% .^{11}$ The recommendation is to consider the early initiation of anticoagulation and its continuation until at least six months post-partum. ${ }^{1,3}$ The treatment of PPCM needs to be continued for 6-12 months. High rate of relapse of heart failure and increases in mortality associated with subsequent pregnancy in the PPCM population, especially in patients with persistent LV dysfunction entering into the next pregnancy. ${ }^{15}$ Hence counselling patients with the history of PPCM on the future pregnancies can be extremely important and a multidisciplinary approach involving an obstetrician, cardiologist, and pediatrician is recommended.

\section{CONCLUSION}

The present study came to conclusion that in rural tertiary centre, maternal outcome and prognosis was poor as patients presenting to us were majority of them in cardiogenic shock and lower LVEF in terminal stages. The associated risk factors were preeclampsia, anemia and multiple gestation which could also contribute to the poor prognosis which was noticed in the study. Early recognition of the disease is of paramount importance as the clinical manifestations can conceal and can lead to high morbidity and mortality especially within 3 months postpartum. Contemplating all these factors, a multidisciplinary approach (a team comprising of cardiologist, perinatologist, obstetrician, and anaesthetist) is required for successful pregnancy outcome.

Funding: No funding sources

Conflict of interest: None declared

Ethical approval: The study was approved by the Institutional Ethics Committee

\section{REFERENCES}

1. Pearson GD, Veille JC, Rahimtoola S, Hsia J, Oakley CM, Hosenpud JD, et al. Peripartum cardiomyopathy: national heart, lung, and blood institute and office of rare diseases (National Institutes of Health) workshop recommendations and review. JAMA. 2000;283(9):1183-8.

2. Hull E, Hafkesbring E. Toxic post-partal heart disease. New Orleans Med Surg. 1937;89:550-7.

3. Demakis JG, Rahimtoola SH. Peripartum cardiomyopathy. Circulat. 1971;44:964-8.

4. Nelson-Piercy C. Heart disease in pregnancy. In: Edmonds DK, editor. Dewhurst's Textbook of Obstetrics and Gynaecology. $7^{\text {th }}$ ed. UK: Oxford, Blackwell Science Ltd; 2007:236-245.

5. Pandit V, Shetty S, Kumar A, Sagir A. Incidence and outcome of peripartum cardiomyopathy from a tertiary hospital in South India. Trop Doct. 2009;39:168-9.

6. Mone SM, Sanders SP, Colan SD. Control mechanisms for physiological hypertrophy of pregnancy. Circulat. 1996;94:667-72.

7. Ansari AA, Neckelmann N, Wang YC, Gravanis MB, Sell KW, Herskowitz A, et al. Immunologic dialogue between cardiac myocytes, endothelial cells, and mononuclear cells. Clin Immunol Immunopathol. 1993;68:208-14.

8. Melvin KR, Richardson PJ, Olsen EG, Daly K, Jackson G. Peripartum cardiomyopathy due to myocarditis. N Engl J Med. 1982;307:731-4.

9. Tidswell M. Peripartum cardiomyopathy. Crit Care Clin. 2004;20:777-88.

10. Williams J, Mozurkewich E, Chilimigras J, Van De Ven C. Critical care in obstetrics: Pregnancy-specific conditions. Best Pract Res Clin Obstet Gynaecol. 2008;22:825-46.

11. Ceci O, Berardesca C, Caradonna F, Corsano P, Guglielmi R, Nappi L. Recurrent peripartum cardiomyopathy. Eur J Obstet Gynecol Reprod Biol. 1998;76(1):29-30.

12. Binu A, Rajan S, Rathore S. Peripartum cardiomyopathy: an analysis of clinical profiles and outcomes from a tertiary care centre in southern India. SAGE. 2019;1-6.

13. Mandal D, Mandal S. Pregnancy and subsequent pregnancy outcome in peripartum cardiomyopathy. J Obstet Gynecol Res. 2011;37(3):22-7.

14. Bhalerao A, Garg R. Pregnancy outcome in peripartum cardiomyopathy. Inter J Obstet Gynaecol Res. 2016;8:38-49.

15. Bhandary A, Rambhatla T. Peripartum Cardiomyopathy: a contemporary review. J Clin Prev Cardiol. 2018;7:54-9.

16. Elkayam U, Padmini P. Maternal and fetal outcomes of subsequent pregnancies in women with peripartum cardiomyopathy. N Engl J Med. 2011;344:67-71.

17. Vani YJ, Vemu A. Maternal and fetal outcome in women with cardiac disease - a retrospective study in tertiary care center. IOSR-JDMS. 2017;16:50-3.

Cite this article as: Singh $\mathrm{S}$, Munikrishna M, Sheela SR. Feto-maternal outcome in patients with peripartum cardiomyopathy: a 5-year study in a tertiary care hospital in Kolar district, India. Int J Reprod Contracept Obstet Gynecol 2020;9:1853-7. 